\title{
COMPLICATIONS OF TONSILLECTOMY AND MANAGEMENT
}

\author{
Arifullah $^{1}$, Sayed Zafar Hassan ${ }^{2}$, Ghulam Muhammad ${ }^{3}$ \\ 1. Town Teaching Hospital \\ 2. District Hospital Kohat \\ 3. Khyber Teaching Hospital
}

\section{ABSTRACT}

\section{OBJECTIVE:}

The objective of the study was to determine the complications of tonsillectomy and management of these the complications.

\section{MATERIAL AND METHODS:}

The study was Randomized controlled trial conducted from 1st January 2008 to 31 December 2009 (of two year duration) at ENT Department Khyber Teaching Hospital, Peshawar. Total 2156indoorpatientsof all age ad both sex, underwent tonsillectomy were included in the study.

\section{RESULTS:}

In my study all of the 2156 patients underwent tonsillectomy were having pain in which 1176 patients (56\%) with mild to moderate pain and 980 patients (44\%) with severe pain, 1274 patients (59\%) nausea and vomiting, 129 patients (7\%) bleeding, 19 patients (<1\%) airway obstruction, 273 patients fever and infection, 17 patients (<1\%) pneumonia, 126 patients (6\%) dehydration, and injury to surrounding structure like teeth injury in 105 patients (5\%), temporary uvular or tongue edema in 367 patients (17\%), and other rare complications (<1\%) like temporomandibularjoint dislocation in 7 patients, Grisel's syndrome in 5 patients, atlanto-axial joint subluxation in 1 patient and glossopharyngeal nerve damage in 3 patients.

\section{CONCLUSION:}

Though tonsillectomy is a routine and safe surgery can result in morbid complications and can cause death. By adopting pre and per-op basic steps can minimize the complications of tonsillectomy.

\section{KEY WORDS:}

Tonsillectomy, Complications of tonsillectomy, pre and post-op steps in tonsillectomy

\section{INTRODUCTION}

Tonsillectomy is one of the most common surgical procedures performed worldwide. ${ }^{1}$ Mortality rates for the operation range from 1 in 10,000 to 1 in 35,000, with morbidity rates ranging

Correspondence:

Dr. Arifullah

Town Teaching Hospital

Contact: 0302-5563597

Email: drmrf@hotmail.com

https://doi.org/10.37762/jgmds.2-1.58 syndrome, atlanto-axial joint emphysema, velopharyngeal incompetence or nasopharyngeal stenosis and otalgia. ${ }^{3}$.The indications for tonsillectomy are tonsillar infections (attacks of acute tonsillitis, peritonsillar abscess unresponsive to medical management and drainage documented by surgeon and chronic or recurrent tonsillitis associated with the streptococcal carrier state), tonsillar hypertrophy (causing

airway obstruction, severe dysphagia, sleep disorders, or cardiopulmonary complications from $1.5 \%$ to $14 \% .{ }^{2}$ The most common complications include pain, bleeding, nausea and vomiting. Less common complications include airway obstruction, fever and infections, pneumonia, dehydration and injury to surrounding structure like teeth, uvula and tongue. The rare complications include temporomandibular joint dislocation, Grisel's int subluxation, glossopharyngeal nerve damage, subcutaneous 
and dental malocclusion or adversely affecting orofacial) and neoplasms (unilateral tonsil hypertrophy or ulceration). ${ }^{4}$

Different techniques of tonsillectomy include, cold steel method (Scalpel, dissector, guillotine), hot diathermy (BiClamp forceps),powered intracapsular. Microdebrider,Harmonic scalpel, Coblation Bipolar and CO2/KTP lasers. ${ }^{5}$ Preoperatively important steps are taken like, overnight observation for high-risk patients with sleep apnea, coagulation disorders, or other underlying diseases, younger than 4 years of age or living a long distance from the hospital. Informed consent bleeding, post-op pain, referred notalgia and dehydration. Inquiry about previous surgeries of any upper airway obstruction, difficulty cervical extension spine, or enzymatic (pseudocholinesterase) deficiencies should be done. Anesthesia fitness like any comorbid disease and Mallampati score ( 1 of 4 classes derived by visualizing the base of the uvula, the tonsillar pillars, and the soft palate) to predict the ease of intubation) Stop page of certain medications like aspirin and other anti-platelet aggregation drugs 7 days before surgery and naproxen and other nonsteroidal anti-inflammatory drugs 4 days before surgery. ${ }^{9}$ Order lab tests like complete blood count, bleeding and clotting times and viral profile (HBsAg, anti-HCV and HIV). ${ }^{10} \mathrm{Neck}$ radiographs should be taken prior to surgery to assess the atlanto-axial joint stability in patients with Down syndrome. ${ }^{6}$, $7,8,9,10$. Per-operatively the use of dexamethasone significantly decrease post-op pain, nausea and vomiting while the grade of surgeon and meticulous surgical technique result in low pain as well as other post-op complications. Other than cold steel method different techniques are used to minimize certain complications of tonsillectomy. ${ }^{11,12}$

Postoperatively pain can be minimized by use of high dose of acetaminophen, (with or without codeine) and celecoxib (selective COX inhibitor). ${ }^{13}$ Honey has also got a valuable effect and can be used as an adjunctive regimen. ${ }^{14}$ Antiemetic use and avoidance of post-op opioids such as codeine or tramadol minimize pos-top nausea and vomiting, ${ }^{15} \mathrm{In}$ less bleeding use of ice cubes, application of local adrenaline pack and IIV trans-aminic acid are affective while in case of excessive bleeding, patient will need to be rushed to an OT to control the bleeding, protecting the airway and stabilizing hemodynamic status. ${ }^{16}$ Acute airway obstruction needs prompt removal of clots, dislodged tonsillar tissue, loose teeth, gauze piece and parts of surgical instrumentation from airway and steroid for edema of the surrounding structures. ${ }^{17}$ Antibiotics is used to reduce the risk of infection in the traumatized region and facilitate a return to normal activity sooner. ${ }^{18}$ Emphysema and pneumo-thorax are treated conservatively with broad-spectrum antibiotics, avoidance of coughing, vomiting, and straining, suturing the injured mucosa and rarely tracheotomy or even a thoracotomy..$^{19}$ Encourage the patients to resume oral intake of fluids and, when necessary, provide analgesia to facilitate the process or re-admit the patient to achieve better pain relief and restore hydration. ${ }^{20}$ Spontaneous healing often occurs within several weeks if taste disorder due to glossopharyngeal nerve damaged during dissection or electrocautery, ${ }^{21}$ Injuries due to hyperextension like mandibular condyle fracture, dislocation or stress injury of the (TMJ) are treated with analgesia, soft diet, and possible surgical reduction, ${ }^{22}$ Atlanto-axial joint dislocation or subluxation and Grisel's syndrome disorder require rest, neck immobilization, and antibiotics. ${ }^{23}$

\section{RESULTS}

In my study out of total 2156 patients, $824(38.2 \%)$ were $5-10$ years, $746(34.6 \%)$ were 11 20 years, $545(25.3 \%)$ were $21-30$ years and $41(1.9 \%)$ were above 30 years of age as shown in table \#1. Both sex groups were included. Out of 2156 patients $1229(57 \%)$ were male and 927 $(43 \%)$ were female as shown in figure \#1. Clinical features in total of 250 patients $2084(96.7 \%)$ were having of sore throat, obstructive symptoms in 245(11.4\%), enlarged tonsils in all 2156 $(100 \%)$, enlarged tonsils in ears in $2156(100 \%)$, palpable cervical (jugulo-digastric) lymph nodes in 1996 (92.6\%) and mouth breather $582(26.9 \%)$ as shown in table \#2. The complications were 
divided into most common, less common and rare. The most common complications rate in my study was that out 2156 patients $1342(62 \%)$ were having post-op mild pain while $288(18)$ severe pain 474 patients (22\%) nausea and vomiting, 323(15\%) mild bleeding (controlled by local measure) while $<1 \%$ severe bleeding (controlled in operation theatre) as shown in table \# 3The less common complications were dehydration in $121(5.6 \%)$, infections in $43(1.9 \%)$, injury to teeth in $56(2.7 \%)$ and edema of uvula in $67(3.1 \%)$. As shown in table \# 4. The rare complication were airway obstruction in $4(0.2 \%)$, TMJ disorder in $2(0.1 \%)$, taste disorder in $1(0.05 \%)$, pneumo-thorax in 2 $(0.1 \%)$, Griesel's syndrome in $1(0.5 \%)$ and atlento-axial dislocation in $1(0.5 \%)$ patients as shown in table \# 5.

Table:1 Age Distribution

\begin{tabular}{|c|c|c|}
\hline Age in Years & Number of patients & $\%$ \\
\hline $5-10$ Years & 824 & $38.2 \%$ \\
\hline $11-20$ Years & 746 & $34.6 \%$ \\
\hline $21-30$ years & 545 & $25.3 \%$ \\
\hline Above 30 years & 41 & $1.9 \%$ \\
\hline
\end{tabular}

Figure \# 1; Sex distribution figure 1

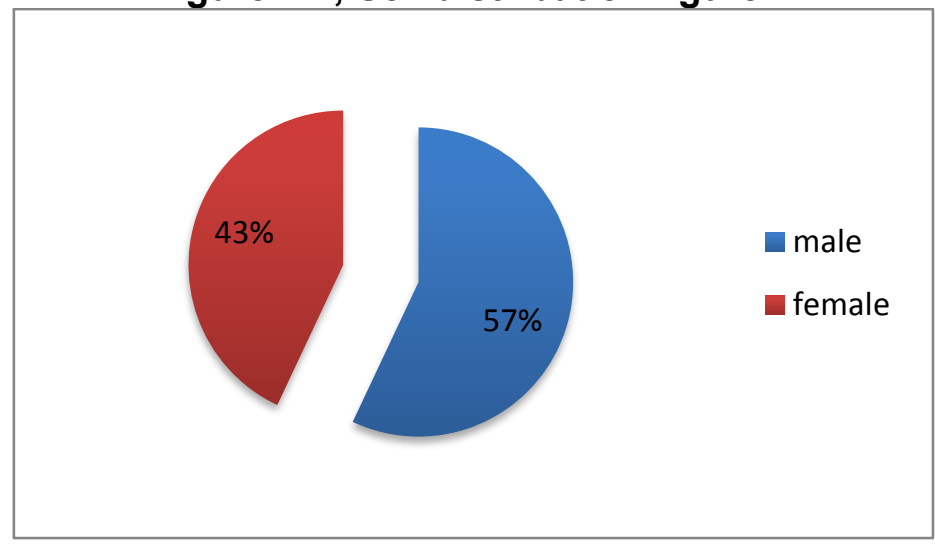

Table: 2 Clinical features

\begin{tabular}{|l|c|l|}
\hline Symptoms & Number of patients & $\mathbf{\%}$ \\
\hline Sore throat & 2084 & $\mathbf{9 6 . 7 \%}$ \\
\hline Obstructive symptoms & 245 & $\mathbf{1 1 . 4 \%}$ \\
\hline Enlarged tonsils & 2156 & $\mathbf{1 0 0 \%}$ \\
\hline $\begin{array}{l}\text { Enlarge jugulodiagastric lymph } \\
\text { nodes }\end{array}$ & 1996 & $\mathbf{9 2 . 6 \%}$ \\
\hline Mouth breathers & 582 & $\mathbf{2 6 . 9 \%}$ \\
\hline
\end{tabular}

Table: 3 The most common complications of tonsillectomy

\begin{tabular}{|l|c|c|}
\hline Complications & Number of Patients & $\%$ \\
\hline Mild pain & 1342 & $62.2 \%$ \\
\hline Severe pain & 288 & $13.3 \%$ \\
\hline Nausea and vomiting & 474 & $21.9 \%$ \\
\hline Mild bleeding & 323 & $10.8 \%$ \\
\hline Severe bleeding & 21 & $<1 \%$ \\
\hline
\end{tabular}

Table \# 4: the less common complications of tonsillectomy 


\begin{tabular}{|l|c|c|}
\hline Complications & Number of Patients & $\%$ \\
\hline Dehydration & 121 & $5.6 \%$ \\
\hline Infections & 43 & $1.9 \%$ \\
\hline Injury to teeth & 56 & $2.7 \%$ \\
\hline Edema of uvula & $\mathbf{6 7}$ & $\mathbf{3 . 1} \%$ \\
\hline
\end{tabular}

Table: 5 rare complications of tonsillectomy

\begin{tabular}{|l|c|c|}
\hline Complications & Number of Patients & $\%$ \\
\hline Airway obstruction & 4 & $.2 \%$ \\
\hline TMJ disorders & 2 & $.1 \%$ \\
\hline Taste disorder & 1 & $.05 \%$ \\
\hline Pneumothorax & 2 & $1 \%$ \\
\hline Griesel's syndrome & 1 & $.05 \%$ \\
\hline Atlento-axial disloation & 1 & $.05 \%$ \\
\hline
\end{tabular}

\section{DISCUSION}

Though tonsillectomy is a routine and safe surgery, but not without complications. Pain, nausea and vomiting, dehydration the morbid complications while bleeding and airway obstructions are the main causes of motility. According to large-scale study, almost all the patients undergone tonsillectomy have mild to moderate pain and nearly $50 \%$ experience severe pain, despite an appropriate around-the-clock dose of acetaminophen with codeine ${ }^{12,13}$ Up to $89 \%$ of children undergoing tonsillectomy have post-op vomiting and nausea. ${ }^{17}$ Bleeding, followed by hypo-volumic shock, is the most common cause of morbidity and mortality among patients undergoing tonsillectomy, affecting an estimated $0.5 \%$ to $10 \%$. Approximately 1 in 200 patients returns to the operating room (OR) so that the bleeding can be controlled. Mortality from bleeding is 2 in 10,000 tonsillectomies. Most cases of fatal post-op bleeding occur within the first 24 hours after surgery ${ }^{19}$, ${ }^{20}$. In USA, overall, $11.6 \%$ of patients revisit to hospital due to complications, which include bleeding (41.3\%), acute pain (22.1\%), and fever/dehydration (13.2\%). Among all tonsillectomies, $4.8 \%$ of adult tonsillectomies presented with a bleeding and overall, $2.2 \%$ underwent a procedure to control bleeding at a first revisit. ${ }^{38}$

One study in India, $9.3 \%$ were readmitted with hemorrhage with cold steel dissection method was $1.5 \%$ compared to $6.7 \%$ for Coblation, $6.3 \%$ for bipolar dissection and $1.9 \%$ for Helica thermal coagulation method. Overall consultants had a post tonsillectomy hemorrhage rate of $5.5 \%$ and middle grades had a rate of $3.7 \% .86 .5 \%$ of the patients were already on routine prophylactic oral antibiotics at the time of presentation with hemorrhage needing surgical arrest and $13.5 \%$ were not on antibiotics. There was statistically significant difference in secondary hemorrhage rate between Coblation and cold steel dissection methods. Coblation tonsillectomies had an increased need for operative intervention to control secondary hemorrhage. Routine use of antibiotic and expertise of operating surgeon had no bearing on secondary hemorrhage rate. ${ }^{39}$ In another study, use of dexamethasone showed significantly less postoperative early vomiting, significantly less pain and less painful swallowing after tonsillectomy. ${ }^{40}$

\section{CONCLUSION}

Though tonsillectomy is a routine and safe surgery can result in morbid complications and can cause death. By adopting important pre and per-op basic steps can minimize the complications of tonsillectomy while proper management of these complications can minimize the resulted morbidity and mortality. 


\section{REFERENCES}

1. Vestergaard H, Wohlfahrt J, Westergaard T, et al. Incidence of tonsillectomy in Denmark, 1980 to2001. Pediatr Infect Dis J. 2007; 26:1117-1121.

2. Bizaki A1, Kääriäinen J, Harju T, Rautiainen M. Head Face Med. 2014 Cohen D, Dor M. Morbidity and mortality of post-tonsillectomy bleeding: analysis of cases. J Laryngol Otol. 2008;122:88-92.

3. Randall DA, Hoffer ME. Complications of tonsillectomy and adenoidectomy Otolaryngol Head Neck Surg. 1998 Jan;118(1):61-8.

4. Ahmed AO1, Aliyu I, Kolo ES. Indications for tonsillectomy and adenoidectomy: our experience. Niger J ClinPract. 2014 Jan-Feb;17(1):90-4. doi: 10.4103/1119-3077.122855.

5. Shah UK, Terk A. New techniques for tonsillectomy and adenoidectomy. Oper Tech Otolaryngol. 2009;20:160-166.

6. Buckley A1, Savage E. Preoperative information needs of children undergoing tonsillectomy.J ClinNurs. 2010 Oct;19(19-20):2879-87. doi: 10.1111/j.1365-2702.2010.03273.

7. Asaf $T$, Reuveni $H$, Yermiahu $T$, et al. The need for routine preoperative coagulation screening tests (prothrombin time PT/ partial thromboplastin time PTT) for healthy children undergoing elective tonsillectomy and/or adenoidectomy. Int J PediatrOtorhinolaryngol. 2001;61:217-222.

8. Brigger MT, Brietzke SE. Outpatient tonsillectomy in children: a systematic review. Otolaryngol Head Neck Surg. 2006; 135:1-7.

9. Mallampati S, Gatt S, Gugino L, et al. A clinical sign to predict difficult tracheal intubation: a prospective study. Can AnaesthSoc J. 1985; 32:429-434.

10. Vinik R, Wanner N, Pendleton RC. Periprocedural antithrombotic management: a review of the literature and practical approach for the hospitalist physician. J Hosp Med. 2009; 4:551-559.

11. C. V. Praveen, SubashiniParthiban, R. M. Terry. Complictions of tonsillectomy. Indian Journal of Otolaryngology and Head \& Neck Surgery January 2013, Volume 65, Issue 1, pp 24-28

12. HashmiMA, Ahmed A,Aslam S, Mubeen M. complications of tonsillectomy. JCPSP 2012, Vol. 22 (8): 505-509.

13. Bean-Lijewski JD, Kruitbosch SH, Lewis Hutchinson L, et al. Post-tonsillectomy pain management in children: Can we do better? Otolaryngol Head Neck Surg. 2007;137:545-551.

14. Hwang SH1, Song JN, Jeong YM, Lee YJ, Kang JM. The efficacy of honey for ameliorating pain after tonsillectomy: a meta-analysis. Eur Arch Otorhinolaryngol. 2014 Dec 19.

15. Sadhasivam S1, Chidambaran V, Olbrecht VA et al. Opioid-Related Adverse Effects in Children Undergoing Surgery: Unequal Burden on Younger Girls with Higher Doses of Opioids. Pain Med. 2014 Dec 17. doi: 10.1111/pme.12660.

16. Arora R, Saraiya S, Niu X, et al. Post tonsillectomy hemorrhage: Who needs intervention? Int J PediatrOtorhinolaryngol. 2014 Dec 8. pii: S0165-5876(14)00651-X. doi: 10.1016/j.ijporl.2014.11.034.

17. Shi ZP, Wang CC, Lee JC, et al. Post-tonsillectomy hematomaof the mouth floor. Eur Arch Otorhinolaryngol. 2006;263:1041-1043. 
18. Clement DM, Supriya WA, McKerrow WS. Antibiotics to reduce post-tonsillectomy morbidity. Cochrane Database Syst Rev. 2008;(2):CD005607.

19. 6. Kim JP, Park JJ, Kang HS, Song MS. Subcutaneous emphysema and pneumomediastinum after tonsillectomy. American Journal of Otolaryngology. 2010;31(3):212-215.

20. Colclasure J, Graham S. Complications of outpatient tonsillectomyand adenoidectomy: a review of 3,340 cases. Ear NoseThroat J. 1990;69:155-160.

21. Goins MR, Pitovski DZ. Post-tonsillectomy taste disorder: a significant complication. Laryngoscope. 2004;114:1206-1213

22. Gupta S, Sing S, Misra T, et al. Fracture of the mandibular condyle as a complication of tonsillectomy. Ear Nose Throat J. 1989;68:477-479.

23. Wilson BC, Jarvis BL. Nontraumatic subluxation of the atlantoaxial joint: Grisel's syndrome. Ann OtolRhinolLaryngol. 1987;96:705-708.

\section{(c) (1) (2) (2)}

LICENSE: JGMDS publishes its articles under a Creative Commons Attribution Non-Commercial Share-Alike license (CC-BY-NC-SA 4.0). COPYRIGHTS: Authors retain the rights without any restrictions to freely download, print, share and disseminate the article for any lawful purpose. It includes scholarly networks such as Research Gate, Google Scholar, LinkedIn, Academia.edu, Twitter, and other academic or professional networking sites. 